\title{
Chemical equilibrium model to investigate scaling in moving bed biofilm reactors (MBBR)
}

\author{
Vasan Sivalingam $^{1} \quad$ Osama Ibrahim $^{1} \quad$ Sergey Kukankov $^{1} \quad$ Babafemi Omodara $^{1}$ Eshetu \\ Janka $^{1}$ Shuai Wang ${ }^{2}$ Carlos Dinamarca ${ }^{1}$ Hildegunn $\mathrm{HH}^{1} \quad$ Rune Bakke $^{1}$ \\ ${ }^{1}$ Department of Process, Energy and Environmental Technology, University of South-Eastern Norway, Norway, \\ eshetu.j.wakjeralusn.no \\ Biowater Technology AS, Norway, sw@biowatertechnology.com
}

\begin{abstract}
Moving bed biofilm reactor (MBBR) is a robust, flexible and compact technology for treatment of medium to high strength wastewater. However, while treating wastewater with high concentration of ammonium, phosphorus and metal ions, scaling on the biofilm carriers can occur, causing biofilm carriers to sink the bottom of reactors. That leads to less carrier motion, higher energy consumption and deteriorated mass transfer, causing lower process efficiency and increased operational cost. This can be a major MBBR operational challenge for certain types of wastewater. In this study, scaling on biofilm carriers in an MBBR reactor treating reject water from anaerobically digested wastewater sludge was investigated. The $67 \mathrm{~L}$ reactor was operated at $16 \mathrm{~h}$ hydraulic retention time (HRT) for over 250 days. The metal ion concentrations in the reject wastewater in and out of the MBBR were analyzed using microwave plasma-atomic emission spectroscopy (MP-AES). The chemical equilibrium simulation tool -Visual MINTEQ 3.1 was applied to determine the possible mineral precipitates. The measured concentrations of $\mathrm{Mg}^{2+}, \mathrm{Ca}^{2+}, \mathrm{Fe}^{3+}, \mathrm{NH}_{4-} \mathrm{N}, \mathrm{PO}_{4}{ }^{3-}, \mathrm{SO}_{4}{ }^{2-}$ and alkalinity from the inlet and outlet of the reactor were used as inputs to the model. Dry biomass and precipitates from biofilm carriers were digested by a DigiPREP digestion system and element analysis performed using MP-AES for simulated data validation. The results show that $\mathrm{Fe}^{3+}$ and $\mathrm{Ca}^{2+}$ had the highest potential to form mineral precipitates and scaling on the biofilm carriers. Hematite, Maghemite, Hydroxyapatite, Geothite and Magnesioferrite were the first five predominant forms of mineral precipitates, in the $\mathrm{pH}$ range from 6.0 to 9.0. The saturation indices (SI) of these five minerals increased with $\mathrm{pH}$, implying that measures to lower $\mathrm{pH}$ may reduce the problem. Digested biomass composition and inorganic solid analysis confirmed that calcium is the major cause for scale formation on the biofilm carriers. Crystal formations in the biofilms were confirmed by optical microscopy images.
\end{abstract}

Keywords: Visual MINTEQ, scaling, moving bed biofilm reactor, reject water

\section{Introduction}

Scaling on biofilm carriers is a major problem in moving bed biofilm reactors (MBBR) treating wastewater with high concentration of ammonium, phosphorus and metal ions. Scale formation occurs, e.g., in treatment of reject water from sludge digestion. When sludge is digested anaerobically, ammonia and soluble orthophosphate will be released from the sludge and end up in the reject water when such sludge is dewatered, and, in the presence of magnesium, calcium or ferric ions, could result in crystallization of inorganic salts. The amount of active biomass is an important factor in assessment the performance of MBBR, and the biomass growth chiefly depends on the designed carrier's effective surface area (ESA). During the MBBR operation, ESA can decrease because of excess biofilm biomass accumulation so that the area of biofilm exposed to the liquid (EBA) decreases. Surplus biofilm thickness may thereby have negative effect on the reactor's efficiency by reducing EBA and mass transfer and also by increasing carrier weight (Ødegaard, 2006; Piculell, 2016).

Crystallization can happen when a solution is supersaturated. This occurs when the solute concentration surpasses the equilibrium and nucleation occurs due to high free energy. Saturation index (SI) is an important parameter for determination of the probability for mineral precipitation. SI is a logarithmic ratio between ion activity product (IAP) and equilibrium constant $\left(\mathrm{K}_{\mathrm{sp}}\right)$ in the wastewater treatment process (Sharp et al., 2013)

$$
\mathrm{SI}=\log \frac{\mathrm{IAP}}{\mathrm{K}_{\mathrm{sp}}}
$$

IAP (ion activity product) is quantified as a product of all comprised ion concentrations which should be measured as soluble ions. Ionic strength $(I)$ depends on dissolved solids concentrations and can be calculated from (2).

$$
I=\frac{1}{2} \sum Z_{i}^{2} C_{i}
$$

Where, $Z_{i}$ is the valency of the ion and $C_{i}$ is the concentration. Ionic strength for wastewater is in the range of 0 to 0.2 . If the composition of wastewater is unknown, it can be approximated as the dissolved solids $[\mathrm{g} / \mathrm{L}]$ x $2.5 \times 10^{-5} \times 2.5 \times 10^{-5}$. Debye-Huckel method 
uses mean ionic activity $(\gamma)$ for activity correction as follows (Cellen, 2010):

$$
\log \gamma=-0.5 Z^{2} \frac{\sqrt{I}}{1+\sqrt{I}}
$$

Visual MINTEQ 1.3 is based on Equations 1-3 and is one of the most used chemical equilibrium simulation tool to determine possible mineral speciation and estimate its solubility at chemical equilibrium. Visual MINTEQ is a simulation tool which can be used to compute the equilibrium composition of dilute aqueous solutions. It is a Windows version of MINTEQA2 equipped with inclusive thermodynamic data to estimate speciation, solubility and equilibrium of minerals in the solutions. It was found to be a good simulation tool in several studies which have been implemented in different versions of Visual MINTEQ to predict and control of possible mineral precipitations in wastewater. Jia (2014), applied Visual MINTEQ 3.0 to analyze the formation of struvite from sludge dewatering effluent from Bolivar wastewater treatment plant in south Australia. Visual MINTEQ 2.23 was used of struvite formation in a wastewater treatment by (Çelen et al., 2007; Çelen and Türker, 2010) to estimate the required modifications for phosphates precipitation in liquid swine manure. Chand (2018), investigated the struvite formation possibility from anaerobically digested sludge by calculating the values of saturation indices with help of Visual MINTEQ 1.3.

In our study, the model is applied with the objective to investigate the possible precipitates in moving bed biofilm reactors (MBBR) treating reject water. The model calculations were done mainly based on chemical element's concentrations of magnesium, phosphorous, ammonium, iron and calcium. The Debye-Huckel method was use for activity corrections during model setup for precipitation prediction (Jia, 2014). Specified temperature, alkalinity and $\mathrm{pH}$ values were used for determination of saturation index (SI).

\section{Materials and methods}

A moving bed biofilm reactor (MBBR) was installed on the lines of reject water directed to main wastewater inlet as shown in Figure 1. The MBBR has a dimension of $\mathrm{LxBxH}=0.35 \times 0.35 \times 0.55 \mathrm{~m}$ (effluent level) with a working volume of $67 \mathrm{~L}$. It was filled with bio carriers to a filling degree of approximately $70 \%$ of the reactor volume. The bio carriers, BWT $\mathrm{S}^{\circledR}$ (Biowater Technology AS), made of high-density polyethylene (HDPE) with dimensions of $14.5 \times 18.5 \times 7.3 \mathrm{~mm}$ and protected surface area of $650 \mathrm{~m}^{2} / \mathrm{m}^{3}$, were used as biofilm attaching substratum. The reactor was fed by centrifuged effluent from anaerobic sludge digestion. Since the centrifuge works intermittently (i.e., 6-9 hours during week days) the reject wastewater is stored in an intermediate bulk container (IBC) onsite to ensure that there is constant supply of feed into the reactor. The reactor was continuously aerated with air flow $26 \pm 2$ $\mathrm{L} / \mathrm{min}$.

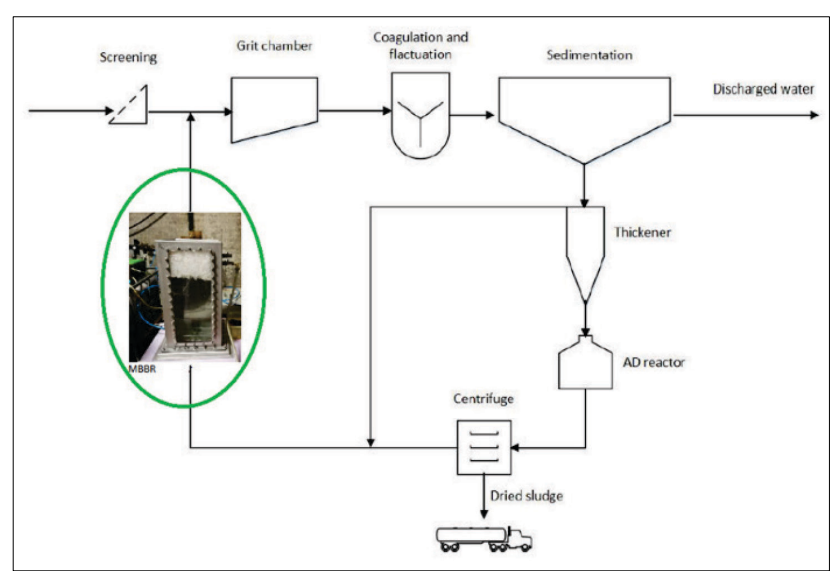

Figure 1. Flow diagram of Knarrdalstrand municipal wastewater treatment plant, Porsgrunn showing the MBBR position.

At the beginning, carriers moved freely in the MBBR reactor as intended but gradually carriers started to sink after strong biofilm growth and eventually settled permanently with heavy scaling on the bottom of the reactor after $\sim 200 \mathrm{~d}$ of operation (Figure 2)

\subsection{Sampling and wet chemical analysis}

Samples of influent and effluent were collected two times per week and various chemical analyses such as ammonium, total chemical oxygen demand (CODt), soluble COD (CODs), total suspended solids (TSS), volatile suspended solids (VSS), $\mathrm{PO}_{4}-\mathrm{P}$ and Alkalinity were carried out. The analyses were performed based on the standard methods according to APHA (1995).

\subsection{Element analysis by Microwave plasma atomic emission spectroscopy}

Microwave plasma atomic emission spectroscopy (MPAES 4210) was used to estimate the total ion concentrations for elements, $\mathrm{Ca}, \mathrm{Fe}, \mathrm{Mg}, \mathrm{P}$ and $\mathrm{Al}$ in the reject water. MP-AES provides analytical techniques to determine the elemental composition of samples by surveying their electromagnetic spectrum or mass spectrum. MP-AES uses nitrogen extracted from air by nitrogen generator to form plasma. Axial magnetic and radial electrical fields strengthen the nitrogen plasma. The sample aerosol was injected into plasma and the axial emission was directed into scanning monochromator. The different elements have a different wavelength. The emissions of selected wavelength range are reflected on high efficiency charge coupled device $(\mathrm{CCD})$ detector. 

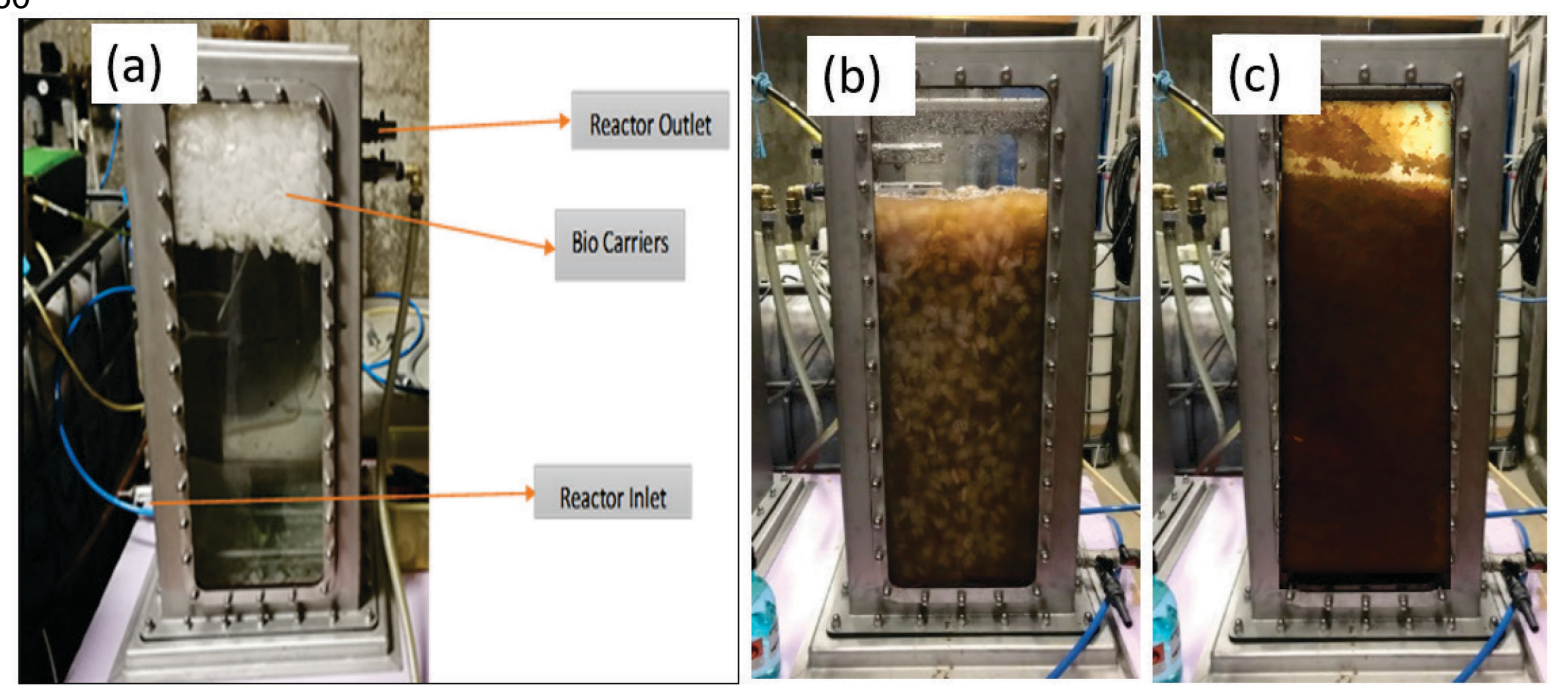

Figure 1. MBBR reactor setup with BWTS $\AA$ carriers (a-MBBR with newly filled carriers, b- MBBR in good condition with freely moving carriers, c- MBBR with settled carriers.

\subsubsection{Liquid sample preparation for element analysis}

Samples from influent and effluent of the reactors were centrifuged, filtered and then diluted with $2 \%$ nitric acid $\left(\mathrm{HNO}_{3}\right)$ to 100 and 1000 dilution factors. Subsequently, the samples were measured by the MP-AES instrument for the elements $\mathrm{Ca}, \mathrm{Fe}, \mathrm{Mg}$ and $\mathrm{P}$. Agilent Technologies ICP-OES Calibration Solution was used for wavelength calibration and Sigma-Alorich Periodic table mix 1 was used for wastewater standard calibration.

\subsubsection{Quantification of biomass on carriers}

Five carriers $(N)$ were taken from the MBBR reactor, placed on an aluminum plate and dried at $105^{\circ} \mathrm{C}$ for 24 $\mathrm{h}$ and cooled down for $10 \mathrm{~min}$ in the desiccator. Then dried carriers were weighted $\left(\mathrm{m}_{1}\right)$. After that, carriers were soaked into hypochlorous acid ( $\mathrm{HOCl}$ ) for 2 hours, biomass was brushed and washed out by tap water. Again, the cleaned carriers were dried at $105^{\circ} \mathrm{C}$ for $24 \mathrm{~h}$ and weighted $\left(\mathrm{m}_{2}\right)$. Eventually, biomass per carrier $m$ was calculated as mentioned in (4).

$$
m=\frac{m_{1}-m_{2}}{N}
$$

Biomass per unit protected surface area was calculated according to (5).

Here:

$$
W=m \cdot \frac{V_{C}}{A}
$$

$W$ : Biomass per unit surface area $\left(\mathrm{g} / \mathrm{m}^{2}\right)$

$m$ : Biomass per carrier (g/piece)

$V_{C}$ : Number of carrier pieces per volume (piece $/ \mathrm{m}^{3}$ )

$A$ : Protected surface area $\left(\mathrm{m}^{2} / \mathrm{m}^{3}\right)$

\subsubsection{Solid sample preparation for element analysis}

A DigiPREP Digestion System was used to digest organic materials included in dried sample of sludge and carrier's biomass. The DigiPREP Digestion System involves a microwave - assisted acid digester (MAAD) equipped with a touch-screen controller, Digi- tubes and filters. Samples from sludge and carriers were dried for at least 10 hours in an oven at $105^{\circ} \mathrm{C}$, then the carriers were rubbed off. Dried samples of mass $0.5 \mathrm{~g}$ were digested with $10 \mathrm{~mL}$ concentrated $\mathrm{HNO}_{3}(69 \% \mathrm{v} / \mathrm{v})$ in special digested tubes placed in a MAAD. Digested samples were cooled and then filtered with $1.2-1.5 \mu \mathrm{m}$ pore size glass filter. Thereafter, samples were diluted up to $50 \mathrm{~mL}$ with distilled water. Again, the diluted samples were diluted with $2 \% \mathrm{HNO}_{3}$ up to 100 and 1000 dilution factor. Subsequently, the samples were measured by MP-AES.

\subsection{Model inputs}

Metal ion concentration, temperature and $\mathrm{pH}$ were the main inputs for Visual MINTEQ simulations. These parameters were varying over the time, therefore average values were used as input for the model. The average temperature was set to $16.5^{\circ} \mathrm{C}$ and $\mathrm{pH}$ was attempted to be kept constant at value8.2. The ion concentration inputs are given in Table 1. Ionic strength was let it to be calculated by model itself based on Debye-Huckel activity model.

Table 1. Input ion concentrations for Visual MINTEQ simulations.

\begin{tabular}{|l|c|}
\hline Elements & Concentration $(\mathrm{mg} / \mathrm{L})$ \\
\hline $\mathrm{Mg}^{2+}$ & 35 \\
\hline $\mathrm{Ca}^{2+}$ & 700 \\
\hline $\mathrm{Fe}^{3+}$ & 15 \\
\hline $\mathrm{NH}_{4}{ }^{+}$ & 440 \\
\hline $\mathrm{P}\left(\mathrm{PO}_{4}\right)$ & 40 \\
\hline $\mathrm{SO}_{4}{ }^{2-}$ & 4 \\
\hline
\end{tabular}

\subsection{Crystal observation in solid samples}

The presence of crystals in biomass and sludge samples was investigated by stereo microscope Nikon SMZ745 and fluorescence microscope Olympus IX70. Both microscopes are equipped with cameras to capture the pictures of biomass at 20x and 40x magnification. 


\section{Results and Discussion}

The effective biofilm thickness is crucial to maintain efficient mass transfer between biofilm and bulk liquid phase. Excessive biofilm accumulation and scaling on the bio-carriers was observed over the study period. For instance, the average values of biomass on carrier per unit surface area exceeded $135 \mathrm{~g} / \mathrm{m}^{2}$ temporarily and stabilized in the range of $90-120 \mathrm{~g} / \mathrm{m}^{2}$ as shown in Figure 3.

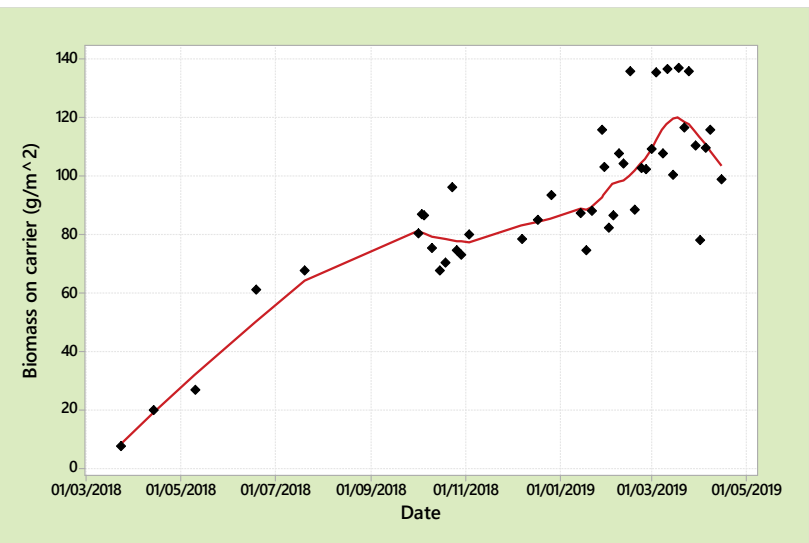

Figure 3. Biomass accumulation on carrier in MBBR reactor over the time $(01.03 .2018-01.05 .2019)$.

Due to the increasing biofilm density it was observed that freely moving carriers started to settle and the effectiveness of the process in removing organics deteriorated (data not shown).

Table 2. Saturation indices for possible mineral precipitates in MBBR reactor, found in simulation result.

\begin{tabular}{|l|c|}
\hline \multicolumn{1}{|c|}{ Mineral } & Saturation Index \\
\hline Hematite & 21.6 \\
\hline Hydroxyapatite & 18.1 \\
\hline Magnesioferrite & 15.8 \\
\hline Maghemite & 14.5 \\
\hline Goethite & 9.6 \\
\hline Lepidocrocite & 9.1 \\
\hline Ferrihydrite $($ aged $)$ & 7.2 \\
\hline $\mathrm{Ca}_{3}\left(\mathrm{PO}_{4}\right)_{2}($ beta $)$ & 6.9 \\
\hline $\left.\mathrm{Ca}_{4} \mathrm{H}_{(\mathrm{PO}}\right)_{3}: 3 \mathrm{H}_{2} \mathrm{O}(\mathrm{s})$ & 6.9 \\
\hline Ferrihydrite & 6.7 \\
\hline $\mathrm{Ca}_{3}\left(\mathrm{PO}_{4}\right)_{2}(\mathrm{am} 2)$ & 5.5 \\
\hline $\mathrm{Strengite})$ & 4.2 \\
\hline $\mathrm{Ca}_{3}\left(\mathrm{PO}_{4}\right)_{2}(\mathrm{am} 1)$ & 2.8 \\
\hline $\mathrm{CaHPO}_{4}(\mathrm{~s})$ & 1.1 \\
\hline $\mathrm{CaHPO}_{4}: 2 \mathrm{H}_{2} \mathrm{O}(\mathrm{s})$ & 0.8 \\
\hline $\mathrm{Struvite}$ & 0.4 \\
\hline
\end{tabular}

The chemical equilibrium model has shown several possible precipitates on the biofilm carriers that may have caused the high biofilm density and carrier settling (Table 2). The results show that $\mathrm{Fe}^{3+}$ and $\mathrm{Ca}^{2+}$ ions had the highest potential to form mineral precipitates and scaling on the biofilm carriers. Among other diverse forms of precipitates, Hematite, Hydroxyapatite, Magnesioferrite, Maghemite, and Goethite were the most predominant forms of mineral precipitates, with saturation indices (SI) of 21.6, 18.1, 15.8, 14.5, and 9.6, respectively. Digested dried sample of sludge and carrier's biomass had $37 \%$ and $28 \%$ mass percentage of calcium, respectively. $\mathrm{pH}$ had effects on the precipitates' $\mathrm{SI}$ in the $\mathrm{pH}$ range from 6.0 to 9.0 are shown in Figure 4.

Struvite was not one of the major precipitates in this study because it has low saturation index 0.4 (Table 2

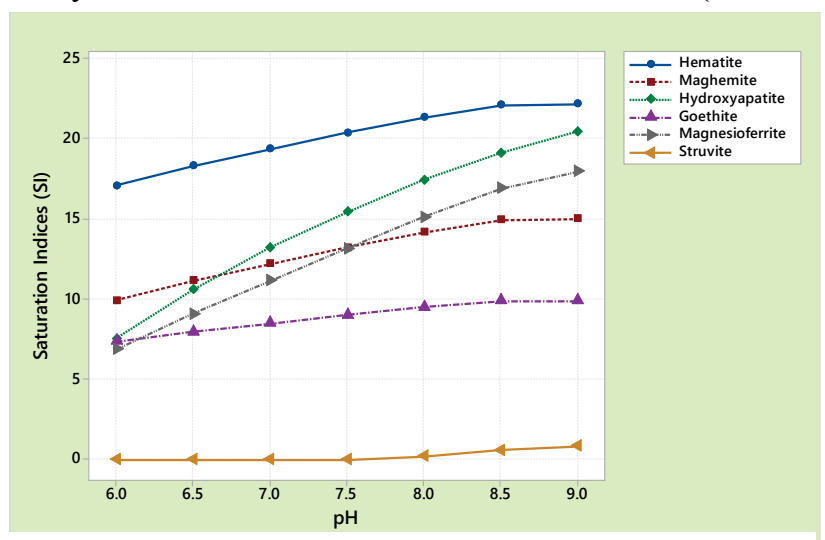

Figure 4. The saturation indices variation with $\mathrm{pH}$ for the predominant mineral precipitates predicted by the model.

and Figure 4). Struvite is magnesium ammonium phosphate and it normally precipitates when the ion concentration of magnesium, ammonium and phosphate are over saturated and the molar ratio is 1:1:1 (Tansel et al., 2018).

The simulations have shown that $\mathrm{pH}$ has significant effect on the amount and type of precipitants on the biofilm carriers. Hematite, Maghemite, Hydroxyapatite and Magnesioferrite precipitation increased most with increase in $\mathrm{pH}$. Goethite and Struvite were not much influenced by $\mathrm{pH}$ with a slight increase in struvite when the $\mathrm{pH}$ was above 8 (Figure 4 ). $\mathrm{pH}$ in the range of 7 to 11 is generally known to be conducive for the formation of struvite, calcium phosphate and calcium carbonate and the crystallization rate decreases when the $\mathrm{pH}$ drops below this 7 to 11 range (Daneshgar et al., 2018). The aeration process in the $\mathrm{MBBR}$ reactor may have increased $\mathrm{pH}$ by $\mathrm{CO}_{2}$ stripping and by biological reactions (Organics consumption, NH4 increase etc.). The measured inlet $\mathrm{pH}$ in this study was $\sim 7.5$ and the reactor $\mathrm{pH}$ was $\sim 8.2$, respectively.

Several studies have shown that crystallization occurs in biofilms when the bulk liquid solution contains more dissolved solute than the equilibrium saturation values. The ions involved in scale formation have intricate interaction and different crystals could be formed 
depending on the system condition such as ionic concentrations, temperature and $\mathrm{pH}$ (Harker et al., 2013).

A microscopic image of the observed crystalsformed in the biofilm carriers is shown in Figure 5.

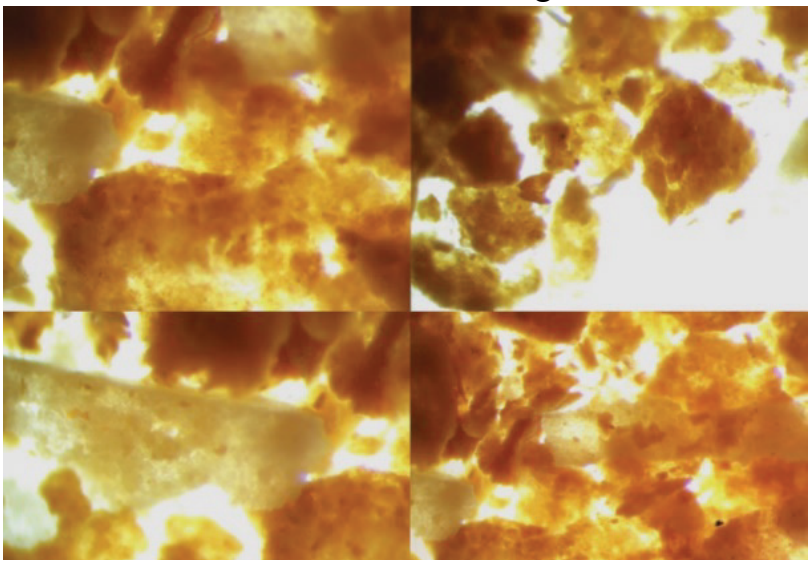

Figure 5. Microscopic observation of crystals on the biofilm carriers. The crystals were the precipitates after washing the biofilm carriers. Image is taken by stereoscopic zoom microscope with C-W10XB adjustable $10 \mathrm{x} / 22 \mathrm{~mm}$ wide field eyepieces and auxiliary objective AL-2x.

The simulation result has showed that, the major proportion of the crystal is a combination of either iron or calcium precipitates. Comparing the microscopic image with other studies of scanning electron microscope the struvite crystallization was significantly low. Since the reject wastewater contains large amount of calcium, it might inhibit the struvite crystallization. Similar studies have indicated that calcium has effect on struvite crystallization at different magnesium to calcium molar ratios (Hao et al., 2008). When the molar ratio of calcium is high, the formed crystal shows transformation in morphology different from struvite.

\section{Conclusions}

Scaling on biofilm carriers of moving bed biofilm reactor (MBBR) is a major problem during treatment of reject wastewater, as it makes biofilm carriers heavy so that they sink to the reactor bottom. The study has confirmed that high concentration of ammonium, phosphorus and metal ions creates scaling on the biofilm carriers.

The chemical equilibrium simulation tool Visual MINTEQ 3.1 is a useful tool to predict which mineral precipitates can occur in wastewater treatment process, to what extent they may form and factors influencing their formation.

The $\mathrm{pH}$ and ionic concentration of metal ions play significant roles in the formation of different crystals. In this study, $\mathrm{Fe}^{3+}$ and $\mathrm{Ca}^{2+}$ had the highest potential to form mineral precipitates and scaling on the biofilm carriers. Among possible forms of precipitates Hematite, Hydroxyapatite, Magnesioferrite,
Maghemite, and Goethite were the most predominant in order of their saturation indices (SI). $\mathrm{pH}$ control, generally by lowering $\mathrm{pH}$, appears to be the most realistic way to limit scaling.

\section{Acknowledgements}

This research project is funded by Oslofjorfondet, project number 269014 under the project title: Efficient upgrading of municipal wastewater treatment plants. Main parts of this study were carried out at Knarrdalstrand wastewater treatment plant, Porsgrunn with contributions from their staff, especially Rune Hogstad Hansen.

\section{References}

American Public Health Association (APHA). Standard Methods for the Examination of Water and Wastewater, $19^{\text {th }}$ ed. American Public Health Association, American Water Works Association and Water Pollution Control Federation, Washington D.C, 1995.

R. Chand. Struvite forming possibility based on the component concentration in liquid phase of anaerobically digested sludge at varying temperature and ph and phosphorus recovery using acetate and tris buffer solution a case study at aalborg west wastewater treat. International Journal of Recent Sci entific Research, 9(7): 28198-28208, 2018.

S. Daneshgar, A. Buttafava, D. Capsoni, A. Callegari, and A. Capodaglio. Impact of $\mathrm{pH}$ and ionic molar ratios on phosphorous forms precipitation and recovery from different wastewater sludges. Resources, 7(4): 71, 2018.

X.D. Hao, C.C. Wang, L. Lan, and M. Van Loosdrecht. Struvite formation, analytical methods and effects of $\mathrm{pH}$ and $\mathrm{Ca}^{2+}$. Water Science and technology, 58 (8): 1687-1692, 2008.

G. Jia. Nutrient Removal and Recovery by the Precipitation of Magnesium Ammonium Phosphate. Faculty of Engineering, Computer and Mathematical Sciences, The University of Adelaide, Adelaide South Australia, 2014.

J.H. Harker and J.F.B. Richardson. Chemical Engineering. Butterworth-Heinemann, Oxford, 2013.

M. Piculell. New Dimensions of Moving Bed Biofilm Carriers: Influence of biofilm thickness and control possibilities, Doctoral Thesis. Department of Chemical Engineering, Lund University, Lund, 2016.

R. E. Sharp, R. Vadiveloo, M. Fergen, P. Moncholi, D. Pitt, M. Wank, and R. Latimer. A theoretical and practical evaluation of struvite control and recovery. Water Environment Research, 85(8): 675-686, 2013.

B. Tansel, G. Lunn, and O. Monje. Struvite formation and decomposition characteristics for ammonia and phosphorus recovery: A review of magnesium-ammoniaphosphate interactions. Chemosphere, 194:504-514, 2018. 
I. Çelen, J.R. Buchanan, R.T. Burns, R. Bruce Robinson, and D. Raj Raman. Using a chemical equilibrium model to predict amendments required to precipitate phosphorus as struvite in liquid swine manure. Water Re search, 41(8):1689-1696, 2007.

I. Çelen, and M.Turker, Chemical equilibrium model of struvite precipitation from anaerobic digester effluents. Turkish J. Eng. Env. Sci., 34:39 - 48, 2010.

H. Ødegaard, Innovations in wastewater treatment: the moving bed biofilm process. Water Science and Technology, 53(9): 17-33, 2006. 